\title{
Development of a Mobile Health Application for HIV Prevention Among At-Risk Populations in Urban Settings in East Africa: A Participatory Design Approach
}

Wilhellmuss Mauka ${ }^{1,2}$, MSc, MD; Christopher Mbotwa ${ }^{3,4}, \mathrm{BSc}, \mathrm{MSc}$; Kåre Moen ${ }^{5}, \mathrm{MD}, \mathrm{PhD}$; Hanne Ochieng Lichtwarck $^{5}$, MD, MPhil; Inga Haaland ${ }^{5}$, BA, MPhil; Method Kazaura ${ }^{3}$, PhD; Germana H Leyna ${ }^{6}, \mathrm{MD}, \mathrm{PhD}$; Melkizedeck T Leshabari ${ }^{1}$, PhD; Elia J Mmbaga ${ }^{3,5}, \mathrm{MD}, \mathrm{PhD}$

\footnotetext{
${ }^{1}$ Department of Behavioural Science, Muhimbili University of Health and Allied Sciences, Dar es Salaam, United Republic of Tanzania

${ }^{2}$ Ministry of Health, Community Development, Gender, Elderly and Children, Dodoma, United Republic of Tanzania

${ }^{3}$ Department of Epidemiology and Biostatistics, Muhimbili University of Health and Allied Sciences, Dar es Salaam, United Republic of Tanzania

${ }^{4}$ Mbeya College of Health and Allied Sciences, University of Dar es Salaam, Mbeya, United Republic of Tanzania

${ }^{5}$ Department of Community Medicine and Global Health, Faculty of Medicine, Institute of Health and Society, University of Oslo, Oslo, Norway

${ }^{6}$ Tanzania Food and Nutrition Centre, Dar es Salaam, United Republic of Tanzania
}

\section{Corresponding Author:}

Wilhellmuss Mauka, MSc, MD

Department of Behavioural Science

Muhimbili University of Health and Allied Sciences

PO Box 65015

Dar es Salaam

United Republic of Tanzania

Phone: 255763225717

Email: wilhemauka@yahoo.com

\section{Abstract}

Background: There is limited evidence in Africa on the design and development of mobile health (mHealth) applications to guide best practices and ensure effectiveness. A pragmatic trial for HIV pre-exposure prophylaxis roll-out among key populations in Tanzania is needed.

Objective: We present the results of the development of a mobile app (Jichunge) intended to promote adherence to pre-exposure prophylaxis (PrEP) among men who have sex with men (MSM) and female sex workers (FSW) in Tanzania.

Methods: A participatory design approach was employed and guided by the information system research framework. MSM and FSW were the target populations. A total of 15 MSM and 15 FSW were engaged in the relevance and design cycles, while the piloting phase included $10 \mathrm{MSM}$ and $20 \mathrm{FSW}$.

Results: The relevance cycle enabled the description of the existing problem, provided the compatible app features for the target population, and identified the need to develop an mHealth app that provides health services in a stigmatizing and discriminating environment. User involvement in the app's design and evaluation provided an opportunity to incorporate social, cultural, and community-specific features that ensured usability. In addition, the participants suggested valuable information to inform the app, text message services, medication registration, and chat platform designs.

Conclusions: The participatory design approach in the development of mHealth apps is useful in identifying and validating population-specific functional features, improve usability, and ensuring future health impacts. Through this participatory process, the Jichunge app took end-user needs, perspectives, and experiences into account, eliciting enthusiasm regarding its potential role in supporting pre-exposure prophylaxis adherence for HIV and related behavioral change promotion.

Trial Registration: International Clinical Trials Registry Platform PACTR202003823226570; https://trialsearch.who.int/Trial2.aspx?TrialID=PACTR202003823226570

(JMIR Form Res 2021;5(10):e23204) doi: 10.2196/23204 


\section{KEYWORDS}

mHealth application; participatory design; HIV; pre-exposure prophylaxis; Africa; female sex workers; sex and gender minorities

\section{Introduction}

As part of a pragmatic trial in Tanzania, this paper describes the process of developing a mobile health (mHealth) application to improve adherence to pre-exposure prophylaxis (PrEP) against HIV among men who have sex with men (MSM) and female sex workers (FSW).

Over the last decade, there has been a steady increase in global mobile phone ownership, including sub-Saharan Africa, which has led to remarkable growth in mobile device use in curative and preventive health care service delivery [1,2]. Short text-based messaging was the mainstay of mobile health communication in the past. However, smartphone applications with increased functionality have become more commonplace in recent years. They have been used to prevent disease and promote health, including sexual and reproductive health [3-7]. mHealth apps have been reported to be useful in disease self-management, customized to clients' and local needs, and providing on-demand interventions as well as communitywide health promotion $[8,9]$.

Among other things, mHealth apps have been used to improve drug adherence in HIV care by reminding clients to take a particular medication, providing health education, and counseling and services [10-12].

A systematic review on mHealth apps in low-income and middle-income countries has reported increased use of various apps focusing on patient care, supporting the health system, and general population health $[13,14]$.

In 2015, the World Health Organization recommended PrEP for HIV prevention among at-risk populations [15]. Like other parts of the world, poor adherence to medication among the high-risk population has been a significant challenge to implementing PrEP intervention in Africa [16-18]. In 2018, Tanzania initiated plans for a PrEP roll-out, but suboptimal adherence due to stigma, stock shortages, forgetfulness in taking daily pills, or attending clinics for medication refills pose a challenge to its effectiveness [19,20].

Since more than half of the mobile subscribers in Tanzania have access to the internet [21], and social network usage is common
[22], mHealth apps offer an opportunity to promote adherence to PrEP in the country.

The reported increase in mobile apps usage for health calls for the documentation of best practices in the development process of these interventions. Such evidence can guide future development and increase the effectiveness of mHealth apps in promoting health. Various development approaches have been evaluated in Asia and the United States, several of which have underlined the critical importance of end-user involvement in the design and development process [23-25]. End-user involvement is paramount when developing mHealth apps targeting populations that face a high level of stigma and discrimination, such as MSM and FSW. While mobile apps have increasingly come into use among stigmatized and criminalized people in sub-Saharan Africa, there is limited data on the development process to inform best practices in the region and among these populations [26]. This paper aims to present the development process of an mHealth app (Jichunge app) for PrEP adherence among MSM and FSW in Tanzania.

\section{Methods}

\section{Design}

A participatory design approach guided by a framework reminiscent of the information system research framework (ISR) was employed in the Jichunge app development [27]. ISR emanates from design science and system engineering commonly used to develop complex information systems [28]. The framework urges end-users' greater inclusion and active participation in designing and evaluating application systems $[23,29]$. The ISR framework consists of three overarching user participatory design cycles. The relevance cycle determines end-user requirements; the design cycle involves prototype development and evaluation; the rigor cycle focuses on assessing underpinning theories (Figure 1). This paper focuses on the relevance and design cycles that are critical in end-product acceptability and usability. Therefore, user involvement was paramount in these undertakings. We supported end-user involvement in the conceptualization, design, and testing by considering their views, perspectives, comments, and suggestions at different levels of the participatory continuum [30]. 
Figure 1. The information system research framework. KB: Knowledge Base.

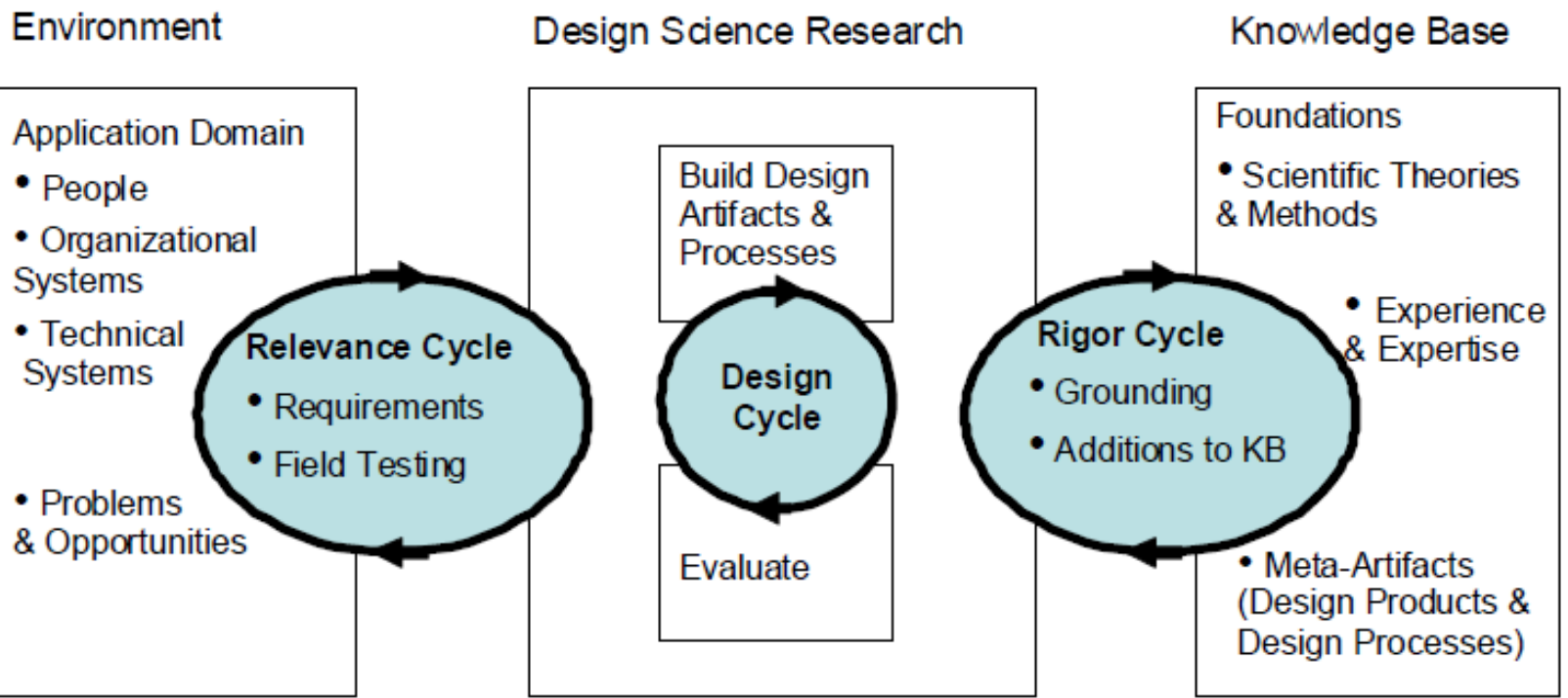

\section{Population}

MSM (men who regularly or occasionally have sex with men) and FSW (women who exchange sex for money or goods) living in Dar es Salaam, Tanzania, participated in this study as members of the target population or end-users. Eligibility involved being at least 18 years and a resident of Dar es Salaam, the largest metropolitan city in Tanzania. The resident was defined as having an address and having lived in the city for the past 6 months preceding the study.

Additionally, at each stage of development, the app was reviewed by a team of experts in HIV behavior and research in key populations. The prototype evaluators involved a multidisciplinary team consisting of PhD students, medical researchers, epidemiologists, biostatisticians, public health specialists, and clinical research coordinators.

\section{Participant Sampling and Recruitment}

Purposive sampling was used to enroll members of the target population (participants) into the study. Based on the investigators' previous knowledge of working with the target populations, participants were recruited based on their potential to provide rich information on the issues related to PrEP use, challenges, and opportunities. Moreover, different strata of the population by age and geographical location in the city, mobile phone ownership, leadership position within target population grassroots organizations, and economic structures were critical in providing diverse views on PrEP and mobile phone use to address health challenges among the target population.

\section{Development Process}

\section{Relevance Cycle}

The study gathered and synthesized information related to the Jichunge app's relevance to the target populations through the relevance cycle step. Firstly, the investigators consulted members of the target populations for problem definition and justification of the app's relevance, including need and potential challenges. End-users' consultation aimed to explore their views on adherence to PrEP and whether a mobile app would be relevant in addressing those challenges. Secondly, using investigators' experience working with these population subgroups [31-34], a detailed and appropriate literature review was conducted to validate the challenges in PrEP adherence raised and explore the proposed Jichunge app's needs to address PrEP adherence among the members of the target populations. Furthermore, researchers reviewed literature on mobile phone access and usage involving the target population, using available social media platforms to inform the design and assess future application challenges and opportunities.

\section{Design Cycle}

\section{Creating an App Prototype}

In creating the app prototype, consultation with target populations led to the consideration of developing an app that accommodates both iOS and Android smartphone operating systems available in Tanzania. Due to the potential for limited mobile data among the key population, users recommended developing an application that allows access to app features such as notification messages (reminding them to take their medication) even in the absence of mobile data. Similarly, the app should enable the client to register daily pills taken for drug adherence, monitoring, and virtualizing the pill calendar even when the user lacks mobile data. An app's development with these innovations was led by a company based in Norway with vast software development experiences [35].

\section{Stage I of Testing the Prototype and Modifications: Prototype Preliminary Reviews}

The initial prototype was installed into investigators' mobile phones as a demonstration version with the essential functions. Next, the investigators reviewed the various app functionalities and evaluated their relevance per planned use among the intended study populations. 
Stage II of Testing the Prototype and Modifications: Target Populations Design Inputs

Various external outlooks and logos were designed (Figure 2) and shared with 15 members from each end-user group (MSM and FSW) in informal, exploratory individual and small group

Figure 2. Proposed and designed logos.

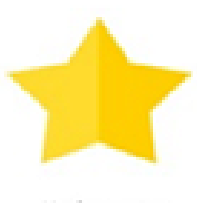

$$
\text { Jichunge }
$$

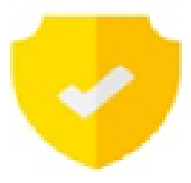

Jichunge

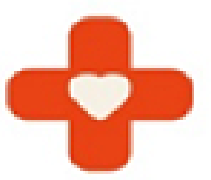

Jichunge

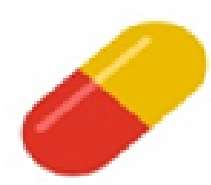

Jichunge discussions. The participants were FSW and MSM with a mean age of 26 years (IQR 20-48), the majority $(18 / 30 ; 60 \%$ ) had completed primary school, and $6.6 \%(2 / 30)$ had a college diploma. In addition, most of the participants $(21 / 30 ; 70 \%)$ were self-employed.
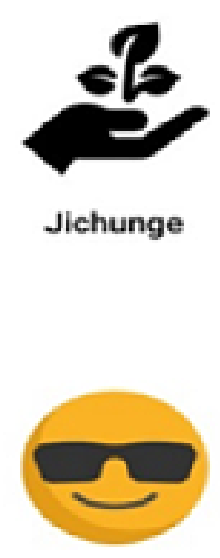

Jichunge

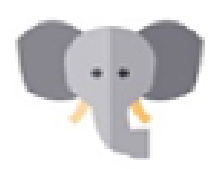

Jichunge

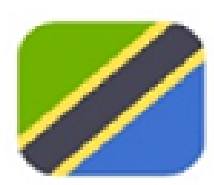

Jichunge
User involvement at this design stage aimed to receive user perspectives, ensure their needs are met, and explore anticipated challenges to inform the app design. End-users' discussion topics in small groups included the app name, layout, and functions. Figure 3 illustrates the sample outlooks and app name as proposed by end-users. All suggestions provided by the end-users were submitted to the software developer for app modification. The intended outcome was to develop an outlook and application name, which is original, user-friendly, and stigma and discrimination-free. 
Figure 3. Previous outlook and name of the app. PrEP: pre-exposure prophylaxis.

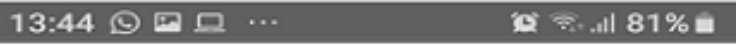

\section{PREPTA}

LEVEL $1 / 5$ points

(a) DAY STREAK 3 days to next level Kâre

Register today's medicine
Health Service (WhatsApp)
Win airtime: The Jichunge
quiz! >
Take part in the weekly Jichunge
quiz to win airtime worth 50oo sh
This is PrEP >
This is how PrEP works to protect
you from HIV
What this app offers >
Check out what the Jichunge app
may offer you
$<\quad ~$
Back
III

\section{Rigor Cycle}

\section{Piloting of the Jichunge App}

The pilot was carried out in Dar es Salaam, where the app will be rolled out and evaluated. FSW and MSM end-user populations were recruited through their peers to participate in the app's piloting phase.

We conducted 2 focus group discussions (FGD) before and after using the app to explore participants' perceptions, experiences, and challenges associated with using the Jichunge app. The FGDs involved 20 members of the HIV at-risk populations (10 FSW and 10 MSM). The participants' median age was 27 years (IQR 21-44), the majority (12/20; 70\%) had completed primary school, and 65\% (13/20) were self-employed. Two PhD students led the FGDs, one as a facilitator and the other as a notetaker.

A demonstration of the app's functionalities and operations was performed for the users, and they were later invited to discuss those functionalities, including expectations regarding the app use. Each of the FGDs took an average of one hour.
Following the FGDs, the Jichunge app was provided to the participants. The app is only available by invitation to ensure that only the target populations can access it and maintain confidentiality. Participants were registered in the web-based portal during the installation, using their mobile phone numbers as illustrated in Figure 4. The installation process took 10 to 20 minutes, depending on the phone type and internet connectivity.

After installation, participants were given 2 weeks to use the app, and they had the opportunity to communicate with a doctor, one of the researchers, and a designated peer educator. During this period, they were also able to consult the research team and the software company.

At the end of the second week, participants were invited for the second round of FGDs. Two FGDs, one for MSM and one for FSW, were conducted. Discussions focused on their experiences, perspectives, and challenges regarding using each of the app's functionalities and features. Suggestions for improvement were also presented to the software developer for improvement. 
Figure 4. Jichunge app web-based admin portal.

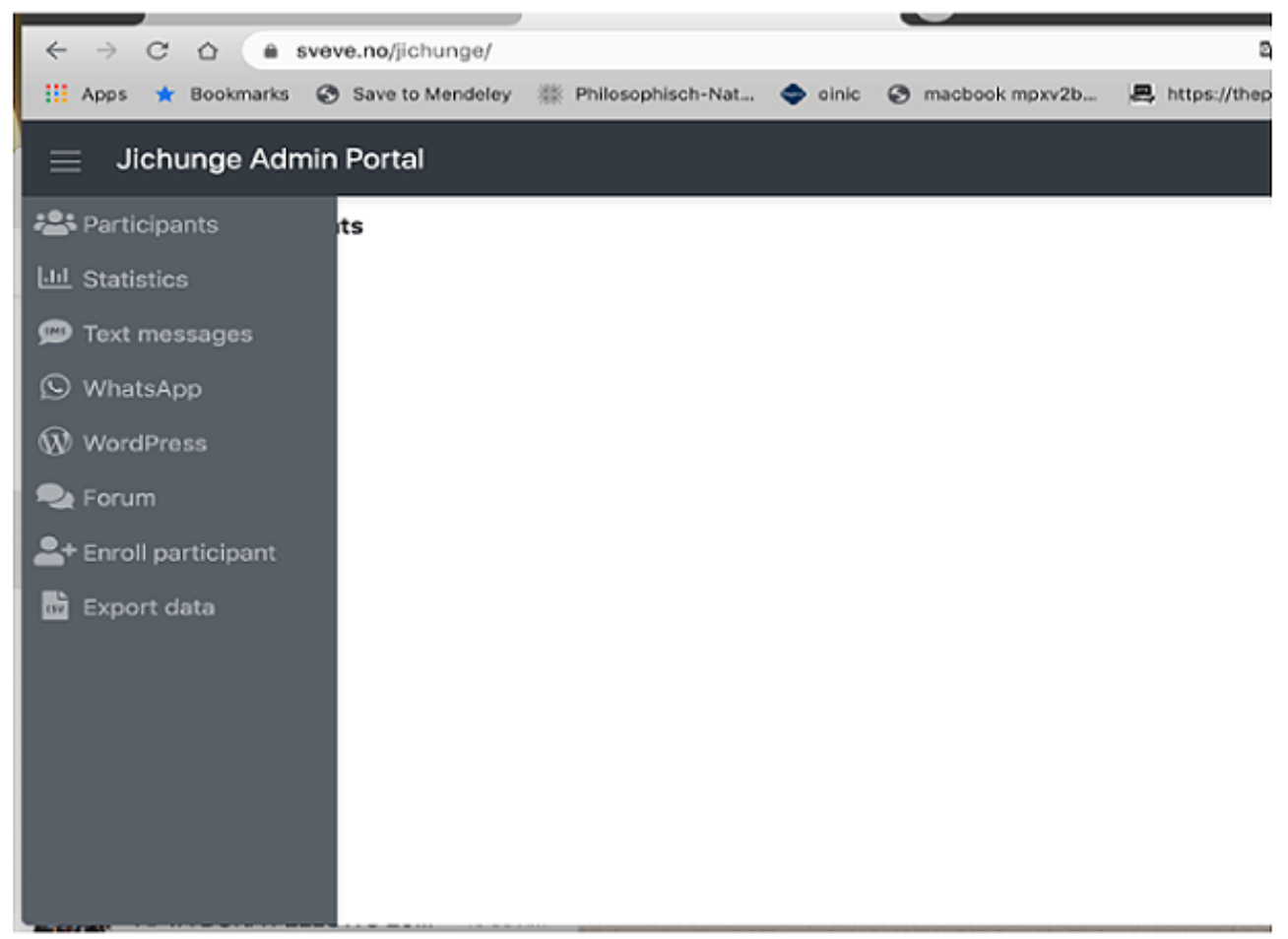

\section{Usability Measures}

The usability was quantitatively measured through user statistics of various app features recorded in the app web-based server. Data were extracted from the web-based server into Microsoft Excel, then entered into Stata (version 13.1; StataCorp) for analysis. The mean number of visits to each of the 9 app features per day was estimated and used to measure and monitor the app's usability.

\section{Data Analysis}

All qualitative data from FGDs and informal exploratory discussions were done in Swahili, the language spoken by all Tanzanians. Data from FGDs were recorded and transcribed verbatim. Field notes were taken during the exploratory individual or small group discussions. Data were later translated to the English language before conducting a content analysis. We applied an open coding approach during the initial data collection stage, where emerging subthemes were identified. Various emerging and related subthemes were subsumed into broader themes relevant to the app's design, functions, and usability. These themes were later summarized and discussed by at least 2 researchers. Relevant quotes for each of the themes were summarized and used in the manuscript. Descriptive analysis was done for quantitative data. Proportions were calculated for categorical variables, and mean or median were estimated for continuous variables as deemed appropriate. The study was approved by the National Health Research Ethics committee, Tanzania (NIMR/HQ/R.8a/Vol.IX/3454).

\section{Results}

\section{Relevance Cycle}

The results are presented based on the ISR framework cycles adopted in the Jichunge app development process. End-users' consultation revealed that the high demand for developing and implementing innovative approaches that can assist key populations in health-related matters, including improving uptake and adherence to PrEP. Members of the target population enthusiastically received the idea and expressed their willingness to support such development. Users indicated the need to have a culturally and legally sensitive application that would provide anonymity and safety and yet offer a high level of desired functions to accommodate such anonymity. Following users' suggestions, the investigators proposed indistinct terms to label the target population groups in the app. The literature review indicated limited access to health services among HIV at-risk populations, including FSW and MSM in the African setting [33]. Access to health information and services among these populations in mainstream public health facilities is associated with many difficulties due to stigma and discrimination. Poor adherence to PrEP among at-risk populations was also reported and threatened the effectiveness of this preventive intervention $[26,34,36]$.

\section{Jichunge App Main Functionalities}

The final prototype of the Jichunge app has 10 various functionalities or features, as presented in Textbox 1. The outlook of the app features to the users is displayed in Figure 5. The Jichunge app can provide information on the participant's level of adherence to daily PrEP pills, allow gamification and winning of prizes, register pills taken, allow setting up of timed 
reminder messages, send a customized reminder message to the user, provide a platform for real-time communication between the user with a peer educator or a health care worker, provide health education, and allow participation in various quizzes.

Textbox 1. A summary of the Jichunge app's main functionalities. PrEP: pre-exposure prophylaxis.

Levels and points: Shows a person's level of adherence per month.

Gamification: Provides a virtual view of the medication registration progress and displays a winning trophy that automatically enters the user in gamification, allowing them to win various prizes, including mobile airtime, data, and others.

Drug registration: The user registers each time they take the medication for records.

Medication time reminder: The user can set up a personal time to be reminded to take the medication daily.

Notification: It notifies the user to take and register the medication per the medication reminder.

Communication with peers (WhatsApp feature): It offers the users an opportunity to communicate in real-time with a trained peer educator about PrEP and other health service-related opportunities and challenges. They are also able to discuss different social issues of relevance to the key population for HIV.

Communication with a health care provider (WhatsApp): It offers users an opportunity to communicate in real-time with a health care provider (doctor) on PrEP and other health-related issues.

Discussion forum (chat room feature): A platform where users can chat with peers anonymously using autogenerated aliases.

Educational materials (WordPress feature): The Jichunge app will contain educational documents and pictorial presentations providing information on learning about PrEP and common questions regarding PrEP. This platform provides users with information on PrEP-related issues.

Jichunge quiz: Users can take a quiz and have a chance to win airtime.

Figure 5. Final outlook and functionalities of Jichunge app. PrEP: pre-exposure prophylaxis.

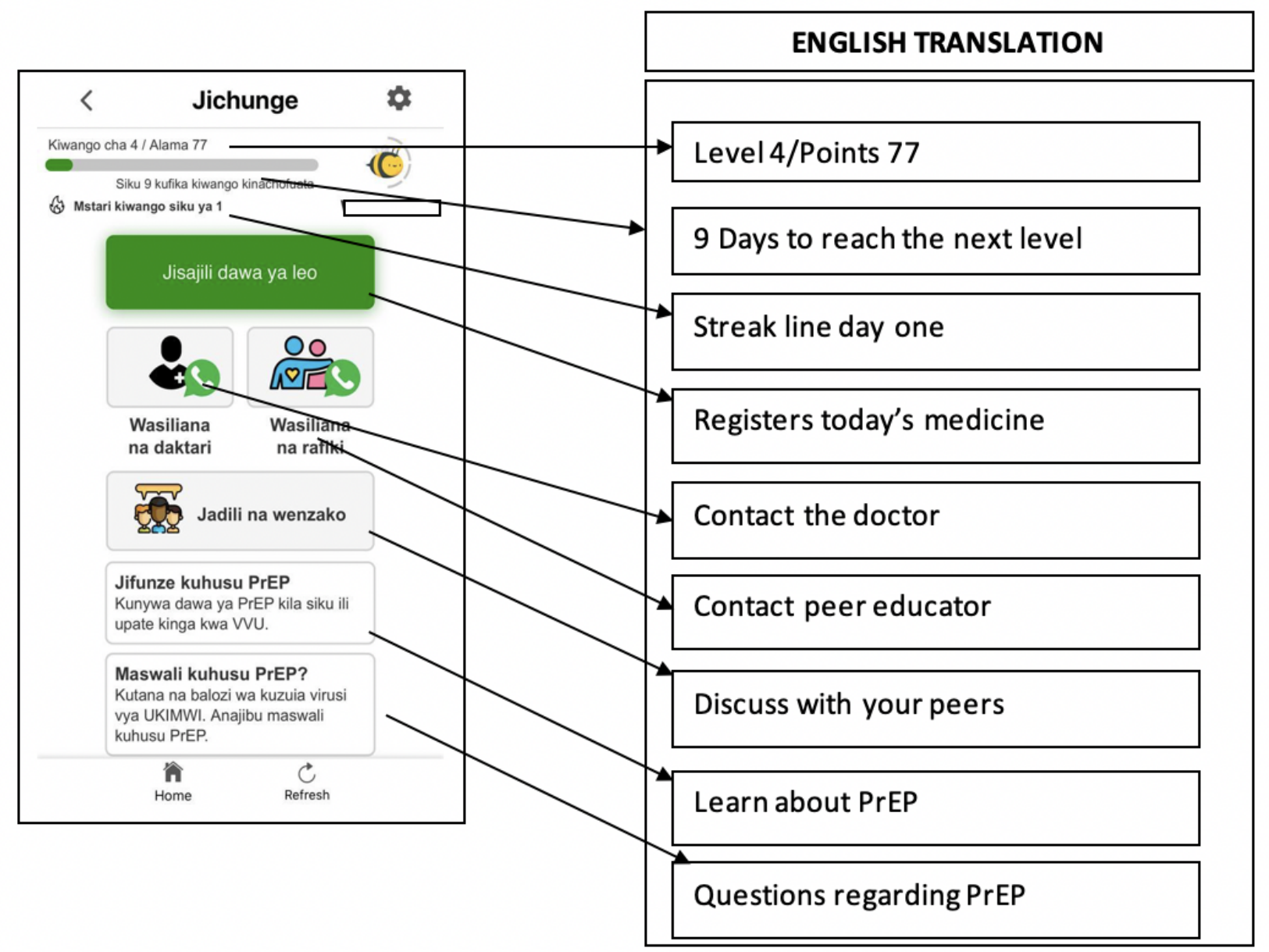




\section{Rigor Cycle}

\section{Participants' Reported Experiences Using the Jichunge App}

Overall, participants expressed their satisfaction with the Jichunge app and expressed their readiness to continue app use. Some reported having proposed the app's usefulness to their peers who were not part of the pilot study. Participants praised the reminder messages as being extremely useful. Even if they did not have internet connectivity or airtime to receive the message, one participant stated:

I have never received the message but, since I like to use the phone, once I see the app's logo, I remember to take medicine. [FSW FGD, participant 1]

Access to educational content about PrEP and other HIV-related information was of most interest to the participants. In addition, the app served as a reference and source of information whenever misunderstandings among members of the at-risk population arose.

\section{...I learn and know more about PrEP, you find many things, considering there are things we are asked in the group. If there is a question that has been asked and you don't know the answer, you go there (into the app), check, and come back to tell your colleagues. [MSM FGD, participant 1]}

Both MSM and FSW were excited about the app. They reported that the outlook (logo) of the app, its features, and built-in anonymity (members only) make it secure and confidential, protecting their discussions and identities. An FSW from the FGD narrated.

...This is going to keep our secrets because they will not be able to just get it like eh! this WhatsApp. For us, it looks like a baby app, the logo leaf, we are mothers, so this is good and secretive. [FSW FGD; participant 6]
Users who provided feedback generally expressed positive attitudes and acceptability of the app design and functions. Suggestions for app improvement included redesigning the discussion forum to match the WhatsApp platform, with which many study participants were acquainted. Users also had some suggestions on the features that should be improved, including the appearance of chat forums on its appearance and showing current online users.

...This discussion forum is not somehow appealing... Once you enter, you should at least know how many are online...Sometimes you don't see the message of other people. [MSM FGD, participant 3]

Moreover, users proposed changes in the gamification score indicators to resemble everyday objects in their environments, such as a ladder, speedometer, or a trophy used in football games. End-users endorsed the app's name, Jichunge, a Swahili word meaning "protect yourself." Population-specific and sensitive language translation from English to Swahili (Tanzania's national language) was also incorporated in the app.

\section{Usability Measures}

The Jichunge app pilot study recorded 68 pill registrations during the first 7 days, and on average, half of the users (10/19, $52 \%)$ registered the medicines taken per day. A third of the users $(6 / 19,31.6 \%)$ had complete registration of their daily pill taking. There were variations in daily pills registrations among the 19 participants, with $6(31.6 \%)$ registering during the first day and $12(63.2 \%)$ on the second day, followed by $8(42.1 \%)$, $11(57.9 \%), 10(52.6 \%), 11(7.9 \%)$, and $12(63.2 \%)$ during subsequent days (Table 1). The users used, on average, 1 out of 9 app features per day. The features visitation rates were highest for WhatsApp (100/270, 37.0\%) and WordPress $(102 / 270,37.8 \%)$. WhatsApp's platform provided secure communication with a peer educator or a doctor, while WordPress contained educational materials about PrEP (Figure $6)$.

Table 1. Number of pill registrations per day during the first week of February 2020.

\begin{tabular}{ll}
\hline Day & Pill registrations per day $(\mathrm{N}=19), \mathrm{n}(\%)$ \\
\hline 1 & $6(31.6 \%)$ \\
2 & $12(63.2 \%)$ \\
3 & $8(42.1 \%)$ \\
4 & $11(57.9 \%)$ \\
5 & $10(52.6 \%)$ \\
6 & $11(57.9 \%)$ \\
7 & $12(63.2 \%)$ \\
\hline
\end{tabular}


Figure 6. The number of App features used per day 3-10 February 2020 (N=270).

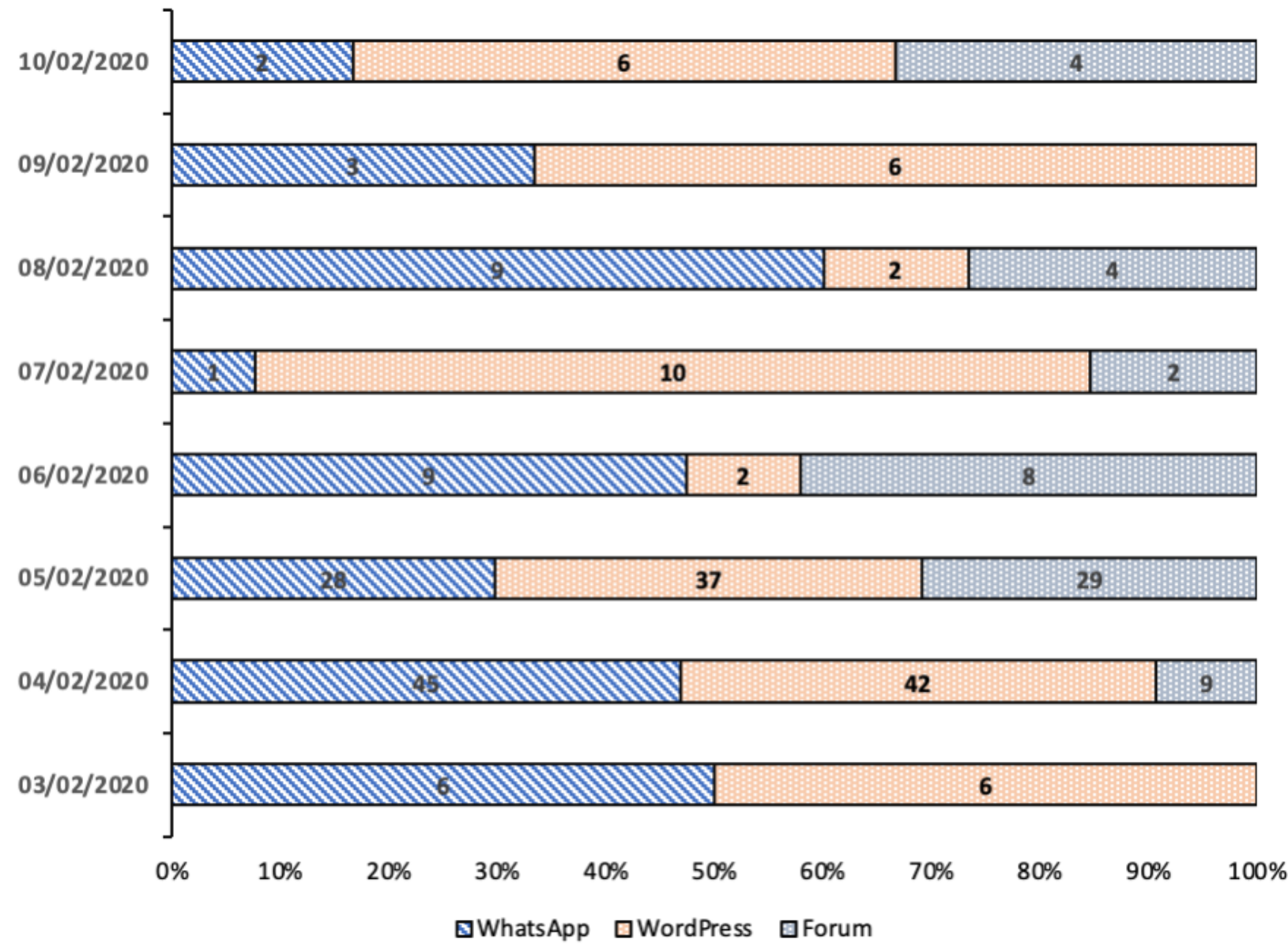

\section{Discussion}

\section{Main Findings}

This paper presents results from a participatory design approach in developing the Jichunge mobile app to improve adherence to PrEP among MSM and FSW in Tanzania. The app includes various functionalities that encourage not only adherence to PrEP but also HIV preventive behaviors. The final version of the application offers 10 unique features, as presented in Textbox 1. The development process, focusing on the relevance and design cycles of the ISR framework, ensured optimal end-user participation in the design and evaluation. MSM and FSW are stigmatized and discriminated against in the sub-Saharan region and Africa as a whole. Their behaviors are deemed illegal, limiting access to population-specific health services $[26,34,36]$. Therefore, innovative approaches are needed to facilitate access and adherence to health-related services such as PrEP for HIV prevention. Studies have indicated that mobile applications developed with adequate consideration of intended users' needs and preferences are more likely to be utilized [37]. Hou et al [38] also stressed the importance of user-centered involvement in developing relevant mHealth apps and ensure usability. The user participatory approach provides an opportunity to validate proposed app features and identify relevant functional features for inclusion in the final design to ensure effectiveness [27,39]. In the Jichunge app, users provided critical inputs on the design, including logo, app name, and features. The participants suggested several modifications, such as text delivery format, gamification, and improvements in the discussion forum. A user-accepted outlook (logo) may go a long way in impacting service use by merely visualizing their phone's logo. An appealing logo stresses the importance of a user-friendly app's appearance in eHealth and mHealth technologies [3].

As expected, the high usability of the application was observed on the daily medicine registration feature. Given that this was the first time these populations in Tanzania used an mHealth application, the results are promising. Moreover, they indicate the potential for future optimal usability. Therefore, an innovative interactive mHealth application may go a long way in strengthening access to health information and access to health services among these populations.

The discussion forum suggested an improvement to include virtualization of other online members, which was considered in the final design to provide a sense of community engagement [40].

Among the lessons learned during the introduction and onboarding of participants into the app was ensuring wireless internet connectivity, which reduces participants' internet costs. Moreover, to ensure that participants have a better opportunity to learn more about the app, promotional posters, app functionality fliers, and demonstration videos should be 
considered alongside verbal descriptions [41,42]. Finally, in a limited resource setting, planning for mobile application intervention may be hindered by outdated versions of mobile phones, which may not be compatible with most modern applications.

\section{Limitations}

The results of this study should be interpreted in light of the following limitations. Firstly, the usability measurement was done through the number of visits to each feature by the user. However, we acknowledge that visit statistics for some features, such as educational resources, may not indicate detailed (quality) reading. It would be more informative to have measures such as design layout, comprehension of learning, and application performance.

Secondly, at both the app design and pilot stage, we had exploratory interviews with only 30 participants and conducted 2 focus group discussions involving 20 participants. Although these participants' sociodemographic characteristics did not differ from that of the user population in the city, we acknowledge that the participants may not represent the views and perspectives of the entire population of FSW and MSM. We used strategic peer-led recruitment (respondent-driven sampling) as the recommended recruitment method in stigmatized, criminalized, and hard-to-reach populations.

Thirdly, the app's reporting of drug use may be affected by a desirability bias, where people may decide to register treatment administration without taking the tablet. Similarly, there could be people who have used the tablet but did not register. As in many desirability-prone studies, confirmatory measures such as pill counts and biological markers are recommended and planned in our future trial using the Jichunge app.

\section{Conclusions}

The participatory design approach in mHealth app development helps assess and cooperate end-users' experiences and perspectives and identify potential challenges to guide future app usability. The Jichunge app accounted for the sociocultural and legal context of the target populations eliciting enthusiasm with the potential to impact adherence to PrEP for HIV prevention and general risk-free behavioral promotion.

\section{Acknowledgments}

The authors would like to thank the Research Council of Norway through the global health and vaccination (GLOBVAC) program and the European and Developing Countries Clinical Trials Partnership (EDCTP2) program supported by the European Union funding for this study. We are also indebted to the participants who provided feedback and input in developing the Jichunge application and the software company Sveve AS of Oslo, Norway, for all their support. The Research Council of Norway partly supports the PREPTA (pragmatic trial for HIV pre-exposure prophylaxis roll-out in Tanzania) project through GLOBVAC (project number 285361). The project is also part of the EDCTP2 program supported by the European Union.

\section{Authors' Contributions}

WM collected and analyzed the data and drafted the initial manuscript. EJM and KM designed the study and interpreted the data. EJM, KM, MTL, GHL, IH, HL, CM, and MK revised the manuscript, along with Neema Makyao and Emmy Metta. All authors read and approved the final version of the manuscript.

\section{Conflicts of Interest}

None declared.

\section{References}

1. World Bank. Information and Communications for Development 2012: Maximizing Mobile. Washington, DC: The World Bank; 2012:116-134 URL: https://documents1.worldbank.org/curated/en/727791468337814878/pdf/ 722360PUB0EPI00367926B9780821389911.pdf

2. PricewaterhouseCoopers. Emerging mHealth: Paths for growth Internet. 201www.pwc.com/mhealth. 2012. URL: https:/ /www.pwc.com/gx/en/healthcare/mhealth/assets/pwc-emerging-mhealth-full.pdf?dLDf=false [accessed 2020-05-24]

3. Anderson PL, Liu AY, Castillo-Mancilla JR, Gardner EM, Seifert SM, McHugh C, et al. Intracellular Tenofovir-Diphosphate and Emtricitabine-Triphosphate in Dried Blood Spots following Directly Observed Therapy. Antimicrob Agents Chemother 2017 Dec 21;62(1):e01710-e01717. [doi: 10.1128/aac.01710-17]

4. Ippoliti N, L'Engle K. Meet us on the phone: mobile phone programs for adolescent sexual and reproductive health in low-to-middle income countries. In: Reprod Health. Meet us on the phone: Mobile phone programs for adolescent sexual and reproductive health in low-to-middle income countries Internet. Reprod Health. BioMed Central Ltd; Jan 17, $2017: 11$.

5. Brown K, Williams DB, Kinchen S, et al. Status of HIV Epidemic Control Among Adolescent Girls and Young Women Aged 15-24 Years — Seven African Countries, 2015-2017. MMWR Morb Mortal Wkly Rep 2018(67):29-32 [FREE Full text] [doi: 10.15585/mmwr.mm6701a6]

6. Feroz A, Abrejo F, Ali S, Nuruddin R, Saleem S. Using mobile phones to improve young people's sexual and reproductive health in low- and middle-income countries: a systematic review protocol to identify barriers, facilitators and reported interventions. Syst Rev 2019 May 18;8(1):117 [FREE Full text] [doi: 10.1186/s13643-019-1033-5] [Medline: $\underline{31103044]}$ 
7. Stephani V, Opoku D, Quentin W. A systematic review of randomized controlled trials of mHealth interventions against non-communicable diseases in developing countries. BMC Public Health 2016 Dec 15;16:572 [FREE Full text] [doi: 10.1186/s12889-016-3226-3] [Medline: 27417513]

8. Becker S, Miron-Shatz T, Schumacher N, Krocza J, Diamantidis C, Albrecht U. mHealth 2.0: Experiences, Possibilities, and Perspectives. JMIR Mhealth Uhealth 2014 May;2(2):e24 [FREE Full text] [doi: 10.2196/mhealth.3328] [Medline: 25099752]

9. Shah R, Watson J, Free C. A systematic review and meta-analysis in the effectiveness of mobile phone interventions used to improve adherence to antiretroviral therapy in HIV infection. BMC Public Health 2019 Jul 9;19(1):915. [doi: 10.1186/s12889-019-6899-6]

10. Mitchell JT, LeGrand S, Hightow-Weidman LB, McKellar MS, Kashuba AD, Cottrell M, et al. Smartphone-Based Contingency Management Intervention to Improve Pre-Exposure Prophylaxis Adherence: Pilot Trial. JMIR Mhealth Uhealth 2018 Sep 10;6(9):e10456. [doi: 10.2196/10456]

11. Liu A, Vittinghoff E, Felten PV, Amico K, Anderson P, Lester R. Randomized Controlled Trial of a Mobile Health Intervention to Promote Retention and Adherence to Pre-exposure Prophylaxis among Young People at Risk for Human Immunodeficiency Virus: The EPIC Study. Clin Infect Dis 2019 May 30;68(12):2010-2017. [doi: 10.1093/cid/ciy810]

12. Ronen K, Unger J, Drake A, Perrier T, Akinyi P, Osborn L, et al. SMS messaging to improve ART adherence: perspectives of pregnant HIV-infected women in Kenya on HIV-related message content. AIDS Care 2018 Apr;30(4):500-505 [FREE Full text] [doi: 10.1080/09540121.2017.1417971] [Medline: 29254362]

13. Forrest JI, Wiens M, Kanters S, Nsanzimana S, Lester RT, Mills EJ. Mobile health applications for HIV prevention and care in Africa. Curr Opin HIV AIDS 2015;10(6):464-471. [doi: 10.1097/coh.0000000000000198]

14. Källander K, Tibenderana J, Akpogheneta O, Strachan D, Hill Z, ten Asbroek AHA, et al. Mobile health (mHealth) approaches and lessons for increased performance and retention of community health workers in low- and middle-income countries: a review. J Med Internet Res 2013 Jan 25;15(1):e17 [FREE Full text] [doi: 10.2196/jmir.2130] [Medline: 23353680]

15. WHO. Guideline on when to start antiretroviral therapyon pre-exposure prophylaxis for HIV. World Health Organization. 2014. URL: https://www.who.int [accessed 2020-05-23]

16. Van der Elst EM, Mbogua J, Operario D, Mutua G, Kuo C, Mugo P, et al. High acceptability of HIV pre-exposure prophylaxis but challenges in adherence and use: qualitative insights from a phase I trial of intermittent and daily PrEP in at-risk populations in Kenya. AIDS Behav 2013 Jul;17(6):2162-2172 [FREE Full text] [doi: 10.1007/s10461-012-0317-8] [Medline: 23080358]

17. Van Damme L, Corneli A, Ahmed K, Agot K, Lombaard J, Kapiga S, et al. Preexposure prophylaxis for HIV infection among African women. N Engl J Med 2012 Aug 2;367(5):411-422 [FREE Full text] [doi: 10.1056/NEJMoa1202614] [Medline: 22784040]

18. Hanscom B, Janes HE, Guarino PD, Huang Y, Brown ER, Chen YQ, et al. Brief report:Preventing HIV-1 Infection in Women using Oral Pre-Exposure Prophylaxis: A Meta-analysis of Current Evidence. J Acquir Immune Defic Syndr 2016;73(5):606-608. [doi: 10.1097/qai.0000000000001160]

19. McCormack S, Dunn DT, Desai M, Dolling DI, Gafos M, Gilson R, et al. Pre-exposure prophylaxis to prevent the acquisition of HIV-1 infection (PROUD): effectiveness results from the pilot phase of a pragmatic open-label randomised trial. The Lancet 2016 Jan;387(10013):53-60. [doi: 10.1016/S0140-6736(15)00056-2]

20. Wheeler DP, Fields SD, Beauchamp G, Chen YQ, Emel LM, Hightow-Weidman L, et al. Pre-exposure prophylaxis initiation and adherence among Black men who have sex with men (MSM) in three US cities: results from the HPTN 073 study. J Int AIDS Soc 2019 Feb;22(2):e25223 [FREE Full text] [doi: 10.1002/jia2.25223] [Medline: $\underline{30768776}$ ]

21. TCRA. Quarterly communications statistics Internet. Tanzania Communications Regulatory Authority. Dar es Salaam URL: https://www.tcra.go.tz/images/documents/telecommunication/TelCom Statistics Dec 2019.pdf [accessed 2020-06-25]

22. GlobalStat. Social Media Stats United Republic Of Tanzania. StatCounter Global Stats Internet. URL: https://gs. statcounter.com/social-media-stats/all/tanzania [accessed 2020-03-23]

23. Kushniruk A, Nøhr C. Participatory Design, User Involvement and Health IT Evaluation. Stud Health Technol Inform 2016;222:139-151. [Medline: 27198099]

24. Chhoun P, Kaplan KC, Wieten C, Jelveh I, Lienemann M, Tuot S, et al. Using participatory methods to build an mHealth intervention for female entertainment workers in Cambodia: the development of the Mobile Link project. mHealth 2019 Aug;5:24-24. [doi: 10.21037/mhealth.2019.07.02]

25. Tang T, Lim ME, Mansfield E, McLachlan A, Quan SD. Clinician user involvement in the real world: Designing an electronic tool to improve interprofessional communication and collaboration in a hospital setting. Int J Med Inform 2018 Feb;110:90-97 [FREE Full text] [doi: 10.1016/j.ijmedinf.2017.11.011] [Medline: 29331258]

26. Johnson CA. Off the Map: How HIV / AIDS programming is failing same-sex practicing people in Africa. International Gay and Lesbian Human Rights Commission, editor. New York, NY: Outright Action International; 2007. URL: http:/ /www.iglhrc.org/files/iglhrc/otm/Off [accessed 2020-05-23] 
27. Schnall R, Rojas M, Bakken S, Brown W, Carballo-Dieguez A, Carry M, et al. A user-centered model for designing consumer mobile health (mHealth) applications (apps). J Biomed Inform 2016 Apr;60:243-251 [FREE Full text] [doi: 10.1016/j.jbi.2016.02.002] [Medline: 26903153]

28. Hevner A. A three cycle view of design science research. Scand J Inf Syst 2007;4(2):1-7 [FREE Full text]

29. Martikainen S, Korpela M, Tiihonen T. User participation in healthcare IT development: a developers' viewpoint in Finland. Int J Med Inform 2014 Mar;83(3):189-200. [doi: 10.1016/j.ijmedinf.2013.12.003] [Medline: 24382475]

30. Ahmed I, Ahmad NS, Ali S, Ali S, George A, Saleem Danish H, et al. Medication Adherence Apps: Review and Content Analysis. JMIR Mhealth Uhealth 2018 Mar 16;6(3):e62 [FREE Full text] [doi: 10.2196/mhealth.6432] [Medline: 29549075]

31. Moen K, Aggleton P, Leshabari MT, Middelthon A. Gays, guys, and mchicha mwiba: same-sex relations and subjectivities in Dar es Salaam. Journal of Homosexuality 2014;61(4):511-539. [doi: 10.1080/00918369.2014.865457] [Medline: 24313863]

32. Mmbaga E, Leyna G, Leshabari M, Moen K. Early Anal Sex Experience Among Men Who Have Sex with Men in Dar Es Salaam Tanzania: Implications for HIV Prevention and Care. Arch Sex Behav 2020 Aug;49(6):2045-2055. [doi: 10.1007/s10508-019-01529-5] [Medline: 31872388]

33. Mmbaga EJ, Moen K, Leyna GH, Mpembeni R, Leshabari MT. HIV Prevalence and Associated Risk Factors Among Men Who Have Sex With Men in Dar es Salaam, Tanzania. JAIDS Journal of Acquired Immune Deficiency Syndromes 2018;77(3):243-249. [doi: 10.1097/qai.0000000000001593]

34. Mmbaga E, Moen K, Makyao N, Mpembeni R, Leshabari M. HIV and STI s among men who have sex with men in Dodoma municipality, Tanzania: a cross-sectional study. Sex Transm Infect 2017 Aug;93(5):314-319. [doi: 10.1136/sextrans-2016-052770] [Medline: 28202736]

35. App designing company. https://sveve.no/. URL: https://sveve.no/varsling. jsp?gclid=EAIaIQobChMIp8jHnv3J6QIVxeAYCh2ApwjiEAAYASAAEgKOsPD BwE [accessed 2020-05-29]

36. Carter M. Activists arrested during attempt to highlight Uganda's neglect of HIV prevention for men who have sex with men Internet. aidsmap. URL: https://www.aidsmap.com/news/jun-2008/

activists-arrested-during-attempt-highlight-ugandas-neglect-hiv-prevention-men-who [accessed 2020-05-24]

37. Brown W, Yen P, Rojas M, Schnall R. Assessment of the Health IT Usability Evaluation Model (Health-ITUEM) for evaluating mobile health (mHealth) technology. J Biomed Inform 2013 Dec;46(6):1080-1087 [FREE Full text] [doi: 10.1016/j.jbi.2013.08.001] [Medline: 23973872]

38. Hou I, Lan M, Shen S, Tsai PY, Chang KJ, Tai H, et al. The Development of a Mobile Health App for Breast Cancer Self-Management Support in Taiwan: Design Thinking Approach. JMIR Mhealth Uhealth 2020 Apr 30;8(4):e15780 [FREE Full text] [doi: 10.2196/15780] [Medline: $\underline{\text { 32352390] }}$

39. Schnall R, Rojas M, Travers J, Brown W, Bakken S. Use of Design Science for Informing the Development of a Mobile App for Persons Living with HIV. AMIA Annu Symp Proc 2014;2014:1037-1045 [FREE Full text] [Medline: 25954413]

40. Yardley L, Spring BJ, Riper H, Morrison LG, Crane DH, Curtis K, et al. Understanding and Promoting Effective Engagement With Digital Behavior Change Interventions. Am J Prev Med 2016 Nov;51(5):833-842. [doi: 10.1016/j.amepre.2016.06.015] [Medline: 27745683]

41. Lefebvre RC, Tada Y, Hilfiker MA, Baur C. The Assessment of User Engagement with eHealth Content: The eHealthEngagement Scale. Journal of Computer-Mediated Communication 2010;15:666-681 [FREE Full text] [doi: 10.1111/j.1083-6101.2009.01514.x]

42. Neve MJ, Collins CE, Morgan PJ. Dropout, nonusage attrition, and pretreatment predictors of nonusage attrition in a commercial Web-based weight loss program. J Med Internet Res 2010 Dec 14;12(4):e69 [FREE Full text] [doi: 10.2196/jmir.1640] [Medline: 21156470]

\section{Abbreviations}

EDCTP2: European and Developing Countries Clinical Trials Partnership

FGD: focus group discussion

FSW: female sex workers

GLOBVAC: global health and vaccination

ISR: information system research framework

mHealth: mobile health

MSM: men who have sex with men

PrEP: pre-exposure prophylaxis 
Edited by G Eysenbach; submitted 04.08.20; peer-reviewed by A Polhemus, B Guthrie; comments to author 14.12.20; revised version received 03.03.21; accepted 01.08.21; published 07.10.21

Please cite as:

Mauka W, Mbotwa C, Moen K, Lichtwarck HO, Haaland I, Kazaura M, Leyna GH, Leshabari MT, Mmbaga EJ

Development of a Mobile Health Application for HIV Prevention Among At-Risk Populations in Urban Settings in East Africa: A

Participatory Design Approach

JMIR Form Res 2021;5(10):e23204

URL: https://formative.jmir.org/2021/10/e23204

doi: 10.2196/23204

PMID:

(C) Wilhellmuss Mauka, Christopher Mbotwa, Kåre Moen, Hanne Ochieng Lichtwarck, Inga Haaland, Method Kazaura, Germana H Leyna, Melkizedeck T Leshabari, Elia J Mmbaga. Originally published in JMIR Formative Research (https://formative.jmir.org), 07.10.2021. This is an open-access article distributed under the terms of the Creative Commons Attribution License (https://creativecommons.org/licenses/by/4.0/), which permits unrestricted use, distribution, and reproduction in any medium, provided the original work, first published in JMIR Formative Research, is properly cited. The complete bibliographic information, a link to the original publication on https://formative.jmir.org, as well as this copyright and license information must be included. 